KONSTAN
JURNAL FISIKA DAN PENDIDIKAN FISIKA
Volume 5, Nomor 2, Desember 2020
$\begin{array}{r}\text { E-ISSN : 2460-9129 dan P-ISSN : 2460-9110 } \\ \text { http://jurnalkonstan.ac.id/index.php/jurnal }\end{array}$

\title{
IDENTIFIKASI MISKONSEPSI DAN PENYEBABNYA PADA MATERI GELOMBANG STASIONER KELAS XI MENGGUNAKAN FIVE-TIER DIAGNOSTIC TEST
}

\author{
Sylvi Aidiya Febriyana ${ }^{1)^{*}}$, Winny Liliawati ${ }^{2)}$, Ida Kaniawati ${ }^{3)}$ \\ ${ }^{1,2,3}$ Program Studi Pendidikan Fisika Universitas Pendidikan Indonesia, Jl. Dr. Setiabudi \\ No. 229 Kota Bandung - 40154, Indonesia
}

\section{Info Artikel}

Sejarah Artikel:

Diterima 7 Agustus 2020

Disetujui 18 September

2020

Dipublikasikan 30

Desember 2020

\section{Kata Kunci:}

Miskonsepsi, Gelombang

Stasioner, five-tier

diagnostic test

\begin{abstract}
Abstrak
Tujuan penelitian ini adalah untuk mengidentifikasi miskonsepsi dan penyebabnya pada materi gelombang mekanik menggunakan five-tier diagnostic test. Metode penelitian yang digunakan yaitu penelitian kuantitatif - deskriptif eksploratif. Penelitian dilaksanakan di empat sekolah menengah atas (SMA) yang ada di Kota Bandung dengan jumlah partisipan sebanyak 155 peserta didik. Instrumen yang digunakan dalam penelitian ini adalah five-tier diagnostic test sebanyak 11 butir soal. Dalam penentuan miskonsepsinya, digunakan kategori peserta didik yang diperoleh dari jawaban peserta didik pada tingkat kesatu sampai tingkat keempat. Sedangkan tingkat kelima digunakan untuk menentukan sumber penyebab yang menyebabkan peserta didik mengalami miskonsepsi. Hasil dari penelitian, ditemukan 5 miskonsepsi yang memenuhi kriteria. diantaranya yaitu M-6.1, M-7.1, M-8.2, M-8.3, dan M-9.2. Penyebab miskonsepsi lebih banyak disebabkan oleh pemikiran sendiri untuk setiap temuan miskonsepsi karena persentase peserta didik dan rata-rata tingkat keyakinan sumber penyebab untuk pemikiran sendiri memiliki nilai yang lebih besar daripada sumber penyebab lainnya. Profil miskonsepsi $30.97 \%$ atau 48 peserta didik untuk M-6.1, $12.90 \%$ atau 20 peserta didik untuk M-7.1, $11.61 \%$ atau 18 peserta didik untuk M-8.2, $12.26 \%$ atau 19 peserta didik untuk M-8.3, dan $15.48 \%$ atau 24 peserta didik untuk M-9.2.
\end{abstract}

(C) 2020 Universitas Islam Negeri Mataram

\footnotetext{
* Corresponding Author: sylviaidiyafebriyana@ student.upi.edu
}

Alamat korespodensi:

Gedung Pasca Sarjana Lantai 3 Kampus 2 UIN Mataram, Jl. Gajah Mada 100 Jempong Mataram, Indonesia

Email: jurnalkonstan@uinmataram.ac.id 


\section{PENDAHULUAN}

Ketika peserta didik berinteraksi dengan lingkungan, peserta didik tersebut akan mendapatkan pengalaman. Tentunya pengalaman ini akan membawa mereka untuk mengembangkan penafsiran-penafsiran atau dugaan-dugaan dari pengalamanketika berinteraksi dengan alamataulingkungan, sehingga dengan intuisi mereka akan terbangun konsepsi awal [1]. Pengalaman dan konsep awal ini memengaruhi kemampuan peserta didik untuk mengingat, menalar, dan memperoleh pengetahuan baru. Menurut penelitian-penelitian dari waktu ke waktu mengenai pembelajaran, mengungkapkan bahwa orang-orang membangun pengetahuan dan pemahaman baru berdasarkan apa yang sudah mereka ketahui dan mereka yakini. Karena pengetahuan baru dibangun dari pengetahuan yang sudah ada, maka banyak yang berpendapat bahwa guru harus memperhatikan pemahaman konsep yang tidak lengkap yang dibawa oleh peserta didik [2]. Dalam pembelajaran yang terjadi di kelas, guru adalah pihak yang paling bertanggung jawab atas hasilnya [3]. Tugas utama seorang guru dalam proses pembelajaran yaitu tidak hanya menyampaikan materi, tetapi juga menanamkan pengertian dan konsep dengan benar. Oleh karena itu, konsep yang tertanam tersebut haruslah benar dan tepat secara ilmiah sehingga tidak menyebabkan salah konsep[4]. Berdasarkan literatur pendidikan, pemahaman konsep yang tidak lengkap disebut sebagai miskonsepsi. Miskonsepsi yang terjadi pada peserta didik tidak terlepas oleh adanya penyebab atau sumber dari ketidak sesuaian konsep yang digunakan dalam pemahaman peserta didik. Penyebab dari miskonsepsi ini dapat disebabkan oleh beberapa faktor, diantaranya yaitu peserta didik, guru, buku teks, dan cara mengajar yang dilakukan oleh guru [5]. Perlunya mengetahui faktor-faktor penyebab munculnya miskonsepsi ini sangat penting untuk melakukan penanganan yang tepat ketika terjadi kekeliruan terkait konsep. Oleh karena itu, pada penelitian ini penulis bertujuan untuk mengembangkan four-tier test menjadi five-tier test. Five-tier test ini merupakan pengembangan dari four-tier test yang ditambahkan angket sumber belajar di tingkat kelima untuk mengetahui penyebab munculnya miskonsepsi yang dialami oleh peserta didik. Begitu banyak miskonsepsi yang terjadi pada mata pelajaran fisika dan salah satu materi yang memungkinkan terjadinya miskonsepsi peserta didik yaitu materi pada gelombang mekanik [6].

Tes diagnostik merupakan salah satu jenis tes yang digunakan untuk mengetahui kelemahan-kelemahan peserta didik sehingga dari kelemahankelemahan tersebut dapat diberikan perlakuan yang tepat [7]. Aspek yang dapat diukur dalam tes ini antara lain untuk mengidentifikasi kesulitan-kesulitan belajar yang dilami peserta didik [8] termasuk mengidentifikasi adanya miskonsepsi yang dialami oleh peserta didik. Menurut perkembangan tes diagnosis, ada beberapa jenis tes yang termasuk kedalam tes diagnosis antara lain yaitu wawancara, tes uraian (pertanyaan terbuka), dan pilihan ganda. Kelemahan dan kelebihan tes ini dijelaskan pada penelitian Kaltacki, Elyilmaz, \& McDermott pada tahun 2015 yang berjudul " $A$ review and comparison of diagnostic instrument to identify students' misconceptions in science". Dalam pengolahannya, penulis menggunakan kategori berdasarkan jawaban peserta didik yang diberikan untuk tingkat kesatu sampai tingkat keempat. Kategori tersebut disajikan pada Tabel 1. 
Sylvi Aidiya Febriyana dk反/KONSTAN Volume 5, Nomor 2 Halaman 42-51

Tabel 1 Kategori Kombinasi Jawaban pada Four-Tier Test [13]

\begin{tabular}{ccccc}
\hline $\boldsymbol{1}^{\text {st }}$ tier & $2^{\text {nd }}$ tier & $\mathbf{3}^{\text {rd }}$ tier & $\mathbf{4}^{\text {th }}$ tier & Kategori \\
\hline Benar & Yakin & Benar & Yakin & SC \\
\hline Benar & Yakin & Benar & Tidak yakin & LK \\
\hline Benar & Tidak yakin & Benar & Yakin & LK \\
\hline Benar & Tidak yakin & Benar & Tidak yakin & LK \\
\hline Benar & Yakin & Salah & Yakin & FP \\
\hline Benar & Yakin & Salah & Tidak yakin & LK \\
\hline Benar & Tidak yakin & Salah & Yakin & LK \\
\hline Benar & Tidak yakin & Salah & Tidak yakin & LK \\
\hline Salah & Yakin & Benar & Yakin & FN \\
\hline Salah & Yakin & Benar & Tidak yakin & LK \\
\hline Salah & Tidak yakin & Benar & Yakin & LK \\
\hline Salah & Tidak yakin & Benar & Tidak yakin & LK \\
\hline Salah & Yakin & Salah & Yakin & MSC \\
\hline Salah & Yakin & Salah & Tidak yakin & LK \\
\hline Salah & Tidak yakin & Salah & Yakin & LK \\
\hline Salah & Tidak yakin & Salah & Tidak yakin & LK \\
\hline & & & &
\end{tabular}

Tabel 1 menunjukkan bahwa untuk kombinasi jawaban peserta didik terdapat lima kategori. Tidak hanya lack of knowledge dan miskonsepsi, tetapi ada false positif dan false negative. False positif adalah jika jawaban (a tier) benar dan alasan ( $r$ tier) salah. Sedangkan false negative jika jawaban (a tier) salah dan alasan ( $r$ tier) benar [9]. Kaltacki-Gurel, Eryilmaz, dan McDermott tahun 2017 merupakan peneliti-peneliti yang mengembangkan four tier test. Dalam penelitiannya, KaltackiGurel, Eryilmaz, dan McDermott mengembangkan instrumen Four-Tier Geometrical Optics Test (FTGOT) yang merupakan tes pilihan ganda empat tahap yaitu tingkat pertama merupakan jawaban peserta didik untuk soal yang diberikan dan tingkat ketiga merupakan alasan peserta didik mengapa memilih jawaban pada tingkat pertama serta tingkat kedua dan keempat merupakan tingkat keyakinan peserta didik menjawab tingkat pertama dan tingkat ketiga.

Pada penelitian ini, penulis mengembangkan tes diagnostik empat tahap (fourtier test) menjadi tes diagnostik lima tahap (five-tier test). Dimana, pada tahap kelima ditambahkan angket terkait sumber yang digunakan peserta didik untuk menjawab pertanyaan pada tingkat pertama dan tingkat ketiga untuk mengetahui penyebab apa yang mendasari peserta didik tersebut mengalami miskonsepsi pada materi gelombang.

\section{METODE PENELITIAN}

Metode yang digunakan dalam penelitian ini yaitu metode kuantitatif deskriptif eksploratif. Bentuk penelitian yang digunakan yaitu non-experimental, yaitu penelitian yang tidak diberikan stimulus atau perlakuan terlebih dahulu terhadap subjek yang akan diteliti, maka pada saat penelitian subjek tersebut dalam 
keadaan natural [10]. Desain penelitian yang digunakan yaitu One-Shot Design yang merupakan penelitian dengan satu kali pengambilan data [11]. Dalam penelitian ini peserta didik diberikan tes diagnostik kemudian diolah untuk mengidentifikasi miskonsepsi yang terjadi dalam materi gelombang stasioner. Sampel yang digunakan dalam penelitian ini yaitu 155 orang peserta didik dengan jumlah laki-laki 65 orang dan perempuan 95 orang yang berasal dari 4 sekolah yang ada di Kota Bandung.

Berikut ini merupakan salah satu contoh instrumen five-tier diagnostic test yang digunakan dalam penelitian untuk mengetahui miskonsepsi yang terjadi pada materi gelombang stasioner.

1.1 Alvin memainkan gitar kesayangannya di belakang rumahnya. Sesekali Alvin memetik gitarnya agar menghasilkan suara yang nyaring dan merdu, dan Alvin memutar-mutar bagian ujung gitar untuk mengencangkan senar-senar gitarnya. Jika Alvin mengubah tegangan senar menjadi semakin tegang, sedangkan panjang dan massa senar tetap sama, bagaimana besar frekuensi yang dihasilkan?
a. Meningkat
b. Menurun
c. Tetap sama
d. Tidak dapat ditentukan

1.2 tingkat keyakinan menjawab soal 1.1

Sangat tidak yakin

Tidak yakin

Yakin

Sangat yakin

1.3 Alasan:

a. Meningkatnya tegangan, maka meningkat pula kecepatan gelombang

b. Semakin besar tegangan, maka semakin sulit senar untuk bergetar

c. Frekuensi hanya dipengaruhi oleh karakteristik senar gitar

d. Frekuensi berbanding terbalik dengan kecepatan gelombang

1.4 tingkat keyakinan menjawab soal 1.3

\begin{tabular}{|c|c|c|c|}
\hline $\begin{array}{c}\text { Sangat tidak } \\
\text { yakin }\end{array}$ & Tidak yakin & Yakin & Sangat yakin \\
\hline
\end{tabular}

1.5 Sumber yang digunakan untuk menjawab soal 1.1 dan 1.3

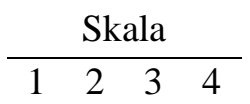
a. Penjelasan guru
b.Pemikiran sendiri
c. Buku
d. Teman 
Sebelum diujikan kepada peserta didik, instrumen di validasi terlebih dahulu kepada tiga orang dosen Fisika di Universitas Pendidikan Indonesia. Dalam membuktikan validitas isi pada setiap butir soal yang digunakan pada instrumen, penulis menggunakan pendekatan Aiken's V. Aiken (1985) merumuskan Aiken's V tersebut untuk menghitung content-validity coefficient yang didasarkan pada hasil penilaian dari para ahli sebanyak $n$ orang terhadap suatu item dari segi sejauh mana item tersebut mewakili konstruk yang diukur (Hendryadi, 2017). Berikut ini merupakan rumus yang digunakan $V=\frac{\sum s}{n(C-1)} ; s=r-I_{0}$. Dengan $V$ merupakan ideks validasi butir; $\mathrm{r}$ merupakan skor kategori pilihan rater; $I_{0}$ merupakan skor terendah kategori penyekoran; $C$ merupakan banyaknya kategori yang dapat dipilih rater; dan $n$ merupakan banyaknya rater. Setelah nilai dari indeks $\mathrm{V}$ diperoleh, kemudian nilai tersebut diklasifikasikan validitasnya. Pengklasifikasian untuk validitas isi instrumen seperti yang ditunjukan pada Tabel 2 .

Tabel 2. Klasifikasi Validitas Isi Instrumen

\begin{tabular}{ccc}
\hline No & Indeks Aiken $(\mathbf{V})$ & Validitas \\
\hline 1 & $0 \leq \mathrm{V}<0,4$ & Kurang valid (rendah) \\
\hline 2 & $0,4 \leq \mathrm{V}<0,8$ & Cukup valid (sedang) \\
\hline 3 & $0,8 \leq \mathrm{V} \leq 1$ & Sangat valid (tinggi) \\
\hline
\end{tabular}

Dari hasil perhitungan berdasarkan hasil validasi, didapatkan rata-rata $V$ sebesar 0.82 dan dapat dinyatakan bahwa instrumen tersebut termasuk kedalam klasifikasi sangat valid yang artinya instrumen dapat digunakan pada penelitian.

Reliabilitas berkaitan dengan taraf kepercayaan. Suatu tes dapat dikatakan memiliki taraf kepercayaan yang tinggi jika tes tersebut memberikan hasil yang tetap atau dengan kata lain tes tersebut memiliki tingkat keajegan yang baik [7]. Analisis yang digunakan dalam pengujian reliabilitas instrumen dalam penelitian ini yaitu dengan menggunakan Cronbach Alpha yang terdapat dalam aplikasi rasch. Nilai Cronbach Alpha ini digunakan untuk mengukur reliabilitas interaksi antara person dan butir soal secara keseluruhan (Sumintono \& Widhiarso, 2015). Berikut ini disajikan hasil reliabilitas untuk person dan butir soal pada Tabel 3.

Berdasarkan hasil analisis yang terdapat pada Tabel 3, di peroleh nilai Cronbach Alpha untuk soal pada tingkatan kesatu yaitu sebesar 0.55 , nilai ini termasuk kedalam kategori yang jelek. Untuk tingkat ketiga yaitu 0.36, nilai ini termasuk kedalam kategori yang buruk. Sedangkan untuk gabungan dari tingkat kesatu dan ketiga dihasilkan nilai 0.65 , nilai ini termasuk kedalam kategori yang cukup. Maka dari itu, meskipun jika dilihat dari setiap tingkat nilai yang dihasilkan Cronbach Alpha berada pada kategori kurang dari cukup, akan tetapi jika kedua tingkatan digabungkan menghasilkan Cronbach Alpha yang cukup dan artinya, soal tersebut memiliki keajegan yang cukup. Untuk separation, pada setiap tingkatan yang diolah memiliki nilai yang semakin besar untuk peserta didik. Hal ini dapat dikatakan bahwa semakin besar nilai separation, maka mampu menunjukan kualitas instumen butir soal yang digunakan sangat bagus. Sebab, dapat mengidentifikasi kelompok butir soal dan kelompok responden. Reliabilitas untuk peserta didik dari tingkat kesatu, tingkat ketiga, dan gabungan tingkat kesatu dan ketiga termasuk 
kedalam kategori yang lemah sedangkan untuk reliabilitas butir soal pada tingkat kesatu yaitu 0.75, termasuk kedalam kategori cukup. Sedangkan untuk tingkat ketiga dan gabungan antara tingkat kesatu dan ketiga yaitu masing-masing 0.83 dan 0.87 , termasuk kedalam kategori yang bagus.

Tabel 3. Hasil Reliabilitas Person dan Butir Soal

\begin{tabular}{cllll}
\hline & & \multicolumn{2}{c}{ Peserta Didik } & Soal \\
\hline \multirow{3}{*}{ Tier 1} & Cronbach Alpha & & 0.55 & \\
\cline { 2 - 4 } & Separation & 0.83 & 1.73 \\
\cline { 2 - 4 } & Reliability & 0.41 & & 0.75 \\
\hline \multirow{3}{*}{ Tier 3 } & Cronbach Alpha & & 0.36 & \\
\cline { 2 - 4 } & Separation & 0.59 & & 2.18 \\
\cline { 2 - 4 } & Reliability & 0.26 & 0.83 \\
\hline \multirow{2}{*}{ Tier 1 dan Tier } & Cronbach Alpha & & 0.65 & \\
\cline { 2 - 4 } 3 & Separation & 1.23 & & 2.63 \\
\cline { 2 - 4 } & Reliability & 0.60 & 0.87 \\
\hline
\end{tabular}

Pengumpulan data dilakukan dengan cara melakukan tes diagnosis lima tingkatan (five-tier diagnostic test) yang disebar menggunakan google formulir. Untuk mendapatkan daftar miskonsepsi pada materi gelombang stasioner, penulis terlebih dahulu memberikan skor terhadap jawaban yang diberikan oleh peserta didik. Teknik pemberian skor ini menggunakan angka 1 atau 0. Berdasarkan Teknik pemberian skor yang dilakukan oleh Caleon dan Subramaniam (2010b) [12], jika jawaban pada tingkat pertama (first-tier) atau alasan yang dipilih pada tingkat ketiga (third-tier) benar, maka di beri skor 1 dan jika salah maka diberi nilai 0. Sedangkan untuk tingkat keyakinan (confidence rating) pada tingkat kedua (second-tier) dan tingkat keempat (fourth-tier) yaitu jika peserta didik memberikan skala 1 atau 2 maka diberi kode 0 dan jika memberi skala 3 atau 4 maka diberi kode 1, karena skala 1 yaitu tidak yakin sekali dan skala 2 yaitu tidak yakin. Sedangkan skala 3 yaitu yakin dan skala 4 yaitu yakin sekali. Setelah peserta didik diberikan skor untuk tingkat pertama sampai tingkat keempat, dilanjutkan dengan mengategorikan kombinasi jawaban yang diberikan oleh peserta didik. Teknik pengategorian ini mengadopsi dari penelitian yang dilakukan oleh Kaltakci-Gurel et al. (2015) [13]. Khusus peserta didik yang teridentifikasi mengalami miskonsepsi (MSC), maka dilakukan analisis agar dapat mengetahui miskonsepsi yang terjadi pada peserta didik terkait dengan materi gelombang stasioner.

Untuk penyebab terjadinya miskonsepsi, dapat diketahui dari tingkat kelima (fifth-tier). Pada tingkat kelima ini penulis hanya melihat sumber yang dipilih oleh peserta didik yang mengalami miskonsepsi saja. Masing-masing sumber penyebab dilihat dari berapa banyak peserta didik yang memilih sumber dan dihitung tingkat keyakinan untuk peserta didik yang memilih sumber penyebab tersebut. 


\section{HASIL DAN PEMBAHASAN}

Berdasarkan pengolahan data penelitian yang telah dilakukan dengan menggunakan soal tes diagnosis five-tier kepada 155 orang peserta didik, diperoleh kategori kombinasi jawaban peserta didik seperti pada Tabel 2 berikut ini. Kategori ini didapatkan dari jawaban yang diberikan pada tingkat kesatu sampai tingkat keempat seperti yang disajikan pada Tabel 4.

Tabel 4. Persentase Kategori Peserta Didik

\begin{tabular}{cccccc}
\hline $\begin{array}{c}\text { No } \\
\text { Butir } \\
\text { Soal }\end{array}$ & SC & LK & MSC & FP & FN \\
\hline 1 & $29.03 \%$ & $45.16 \%$ & $10.97 \%$ & $13.55 \%$ & $1.29 \%$ \\
\hline 2 & $16.13 \%$ & $65.16 \%$ & $11.61 \%$ & $6.45 \%$ & $0.65 \%$ \\
\hline 3 & $35.48 \%$ & $49.68 \%$ & $3.23 \%$ & $5.81 \%$ & $5.81 \%$ \\
\hline 4 & $0.65 \%$ & $74.84 \%$ & $16.13 \%$ & $1.94 \%$ & $6.45 \%$ \\
\hline 5 & $5.81 \%$ & $72.26 \%$ & $6.45 \%$ & $2.58 \%$ & $12.90 \%$ \\
\hline 6 & $3.23 \%$ & $51.61 \%$ & $34.19 \%$ & $9.68 \%$ & $1.29 \%$ \\
\hline 7 & $3.87 \%$ & $59.35 \%$ & $26.45 \%$ & $6.45 \%$ & $3.87 \%$ \\
\hline 8 & $1.29 \%$ & $56.77 \%$ & $32.26 \%$ & $3.23 \%$ & $6.45 \%$ \\
\hline 9 & $6.45 \%$ & $64.52 \%$ & $20.00 \%$ & $5.16 \%$ & $3.87 \%$ \\
\hline 10 & $0.65 \%$ & $71.61 \%$ & $17.42 \%$ & $7.74 \%$ & $2.58 \%$ \\
\hline 11 & $6.45 \%$ & $67.74 \%$ & $12.90 \%$ & $3.87 \%$ & $9.03 \%$ \\
\hline $\begin{array}{c}\text { rata- } \\
\text { rata }\end{array}$ & $9.91 \%$ & $61.70 \%$ & $17.42 \%$ & $6.04 \%$ & $4.93 \%$ \\
\hline
\end{tabular}

Dari 155 peserta didik yang mengerjakan tes diagnosis five-tier terdapat $61.7 \%$ atau sebanyak 96 orang termasuk kedalam kategori kurangnya pengetahuan atau lack of knowledge (LK) pada materi yang diujikan. Sedangkan, untuk peserta didik yang paham konsep hanya ada $9.35 \%$ atau sekitar 15 orang saja. $17.42 \%$ atau 27 orang termasuk ke dalam kategori miskonsepsi, 6,04\% atau 9 orang peserta didik termasuk kedalam kategori false positif dan $4,93 \%$ atau 8 orang lainnya termasuk ke dalam kategori false negatif.

Berdasarkan hasil pengolahan data pada tes diagnosis yang telah dilakukan, maka diperoleh profil miskonsepsi yang disajikan dalam Gambar 1. Berdasarkan Gambar 1, miskonsepsi terbesar terdapat pada item soal nomor enam yang berkaitan dengan perambatan gelombang yaitu sebesar $34.19 \%$ dengan jumlah peserta didik 53 orang. Sedangkan yang paling rendah yaitu pada nomor tiga yang berkaitan dengan frekuensi gelombang dengan jumlah peserta didik 5 orang dan persentasese besar 3.23\%. Menurut Caleon \& Subramaniam (2010b) [12] miskonsepsi dapat dinyatakan signifikan jika jumlahnyalebih dari $10 \%$ dari sampel. Oleh sebab itu pada penelitian ini, ditemukan miskonsepsi yang memenuhi kriteria tersebut pada butir soal nomor $1,2,4,6,7,8,9,10$, dan 11 . 


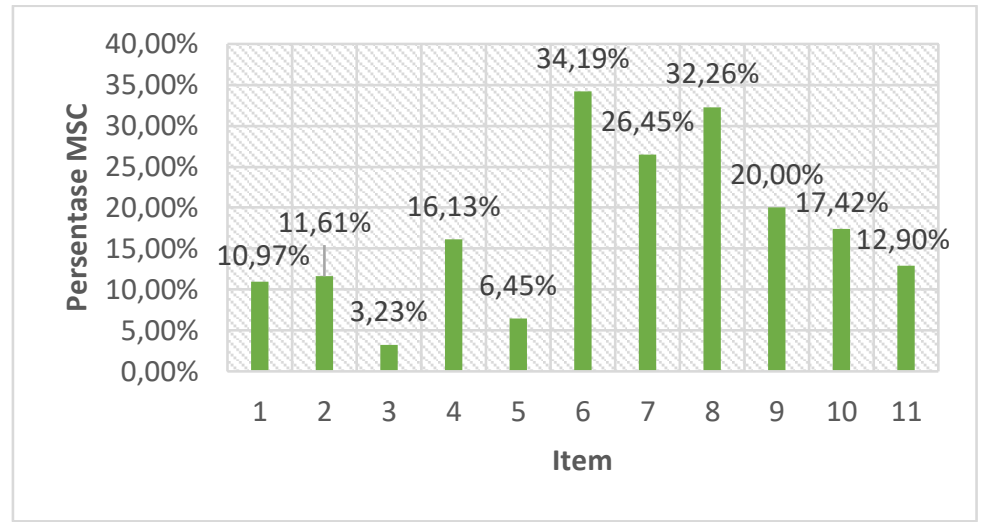

Gambar 1. Profil Miskonsepsi pada Setiap Butir Soal

Dari hasil penelitian tersebut, dilakukan analisis miskonsepsi pada setiap butir soal yaitu dengan melihat alasan yang diberikan peserta didik yang mengalami miskonsepsi untuk mengetahui miskonsepsi apa saja yang banyak dialami peserta didik pada gelombang stasioner. Hasil analisis tersebut, ditemukan 5 miskonsepsi sebagai berikut.

Tabel 2 Temuan Miskonsepsi pada Materi Gelombang Stasioner

\begin{tabular}{|c|c|c|c|}
\hline Kode & Miskonsepsi & $\begin{array}{c}\text { Jumlah } \\
\text { Peserta } \\
\text { Didik } \\
\end{array}$ & Persentase \\
\hline M-6.1 & $\begin{array}{l}\text { Frekuensi dipengaruhi medium } \\
\text { dalam perambatannya }\end{array}$ & 48 & $30.97 \%$ \\
\hline M-7.1 & $\begin{array}{l}\text { Karena gelombang jika } \\
\text { dipantulkan akan membentuk } \\
\text { lembah }\end{array}$ & 20 & $12.90 \%$ \\
\hline M-8.2 & $\begin{array}{l}\text { Memberikan gaya yang besar } \\
\text { untuk menghasilkan pulsa } \\
\text { gelombang yang lebih besar }\end{array}$ & 18 & $11.61 \%$ \\
\hline M-8.3 & $\begin{array}{l}\text { Frekuensi yang } \\
\text { besarmenghasilkan pulsa } \\
\text { gelombang yang cepat }\end{array}$ & 19 & $12.26 \%$ \\
\hline M-9.2 & $\begin{array}{l}\text { Jika tegangannya dijaga konstan, } \\
\text { maka panjang gelombangnya } \\
\text { juga akan tetap }\end{array}$ & 24 & $15.48 \%$ \\
\hline
\end{tabular}

Miskonsepsi terbesar terjadi pada M-6.1 yaitu sebesar $30.48 \%$ atau sebanyak 48 peserta didik dari 155 peserta didik mengalami miskonsepsi terkait dengan perambatan gelombang tali dengan massa yang berbeda. Hal inisejalan dengan penelitian yang dilakukan oleh Yana, Antasari, \& Kurniawan (2019) [14] dan Sutopo (2016) [15]. Selanjutnya, miskonsepsi terkecil terjadi pada M-8.2 yaitu sebesar $11.61 \%$ atau 18 orang peserta didik mengalami miskonsepsi terkait dengan faktor yang mempengaruhi cepat rambat gelombang pada tali. Miskonsepsi ini juga terjadi 
pada penelitian yang dilakukan oleh Caleon dan Subramaniam (2010b) [12] yaitu terkait dengan membuat pulsa gelombang pada tali merambat lebih cepat, maka harus digerakkan lebih cepat dan lebih kuat untuk membuat partikel bergetar dengan amplitudo yang lebih besar dan bergerak dengan energi yang lebih besar. Peserta didik yang mengalami miskonsepsi tersebut disebabkan oleh beberapa faktor seperti penjelasan guru, pemikiran sendiri, buku, dan teman. Tetapi, dalam penelitian ini peserta didik yang mengalami miskonsepsi banyak disebabkan oleh pemikiran sendiri. Penyebab ini diketahui dari tingkat kelima yang ada pada setiap butir soal. Sehingga, kita dapat mengetahui sumber yang menyebabkan peserta didik mengalami miskonsepsi.

\section{SIMPULAN DAN SARAN}

Berdasarkan hasil pengolahan dan analisis data terhadap hasil penelitian, maka dapat disimpulkan bahwa peserta didik paling banyak yang mengalami miskonsepsi sebesar $34.19 \%$ atau sebanyak 53 orang peserta didik dari 155 orang peserta didik yang mengikuti tes. Miskonsepsi terindikasi pada butir soal nomor 1,2,4,6,7,8,9,10 dan 11. Dari Sembilan butir soal tersebut, M-6.1, M-7.1, M-8.2, M-8.3, dan M-9.2 memiliki profil miskonsepsi yang lebih dari $10 \%$ dan termasuk kedalam miskonsepsi yang memenuhi kriteria. Profil miskonsepsi terbesar yaitu ada pada M-6.1 sebesar $30.97 \%$ atau 48 peserta didik mengalami miskonsepsi, dan yang terkecil ada pada M-8.2 yaitu sebesar $11.61 \%$ atau 18 peserta didik.

Sumber penyebab miskonsepsi yang dialami oleh peserta didik beraneka ragam yaitu berasal dari penjelasan yang diberikan guru, pemikiran sendiri, buku yang digunakan dalam pembelajaran, dan jawaban yang diberikan teman. Tetapi dalam penelitian ini, pemikiran sendiri menjadi sumber penyebab miskonsepsi yang dialmi oleh peserta didik. Sumber penyebab ini diperoleh dari tingkat kelima (fifth-tier) pada setiap butir soal tes diagnosis.

\section{DAFTAR PUSTAKA}

[1] Wahyudi, I., \& Maharta, N. (2013). Pemahaman Konsep dan Miskonsepsi Fisika pada Guru Fisika di SMA RSBI Bandar Lampung. Jurnal Pendidikan MIPA, 14 (1), 18-32.

[2] Libarkin, J., \& Kurdziel, J. (2001). Research Methodologies in Science Education: Assessing Students' Alternative Conceptions. Journal of Geoscience Education, 49 (4), 378-383. doi:10.1080/10899995.2001.12028050

[3] Setyadi, E., \& Komalasari, A. (2012). Miskonsepsi Tentang Suhu dan Kalor pada Siswa Kelas 1 di SMA Muhammadiyah Purworejo Jawa Tengah. Jurnal Berkala Fisika Indonesia, 4 (1\&2), 46-49.

[4] Yudhittiara, R. F., Hindarto, N., \& Mosik. (2017). Identifikasi Miskonsepsi menggunakan CRI dan Penyebabnya pada Materi Mekanika Fluida kleas XI SMA. Unnes Physics Education Journal, 6 (2), 22-27.

[5] Suparno, P. (2013). Miskonsepsi dan Perubahan Konsep dalam Pendidikan Fisika. Jakarta: Grasindo. 
[6] Widiyanto, A., Sujarwanto, E., \& Prihaningtiyas, S. (2018). Analisis Pemahaman Konsep Peserta Didik dengan Instrumen Four Tier Diagnostic Test pada Materi Gelombang Mekanik. Seminar Nasional Multidisiplin 2019.

[7] Arikunto, S. (2012). Dasar-dasar Evaluasi Pendidikan. Jakarta: Bumi Aksara.

[8] Hidayati, T., Nugroho, S. E., \& Sudarmin. (2013). Pengembangan Tes Diagnostik untuk Mengidentifikasi Proses Sains dengan Tema Energi pada Pembelajaran IPA Terpadu. Unnes Science Education Journal, 2 (2), 311-319.

[9] Hestenes, D., \& Halloun, I. (1995, November). Interpreting the Force Concept Inventory A response to Huffman and Heller. The Physics Teacher (33), 502506.

[10] Wiersma, W., \& Jurs, S. (2008). Research Methods in Education: An Introduction (9th edition). New York: Pearson.

[11] Sugiyono. (2013). Penelitian Pendidikan Pendekatan Kuantitatif,Kualitatif, dan $R \& D$. Bandung: Alfabeta.

[12] Caleon , I., \& Subramaniam, R. (2010b). Do Students Know What They Know and What They Don't Know? Using a Four-Tier Diagnostic Test to Assess the Nature of Students' Alternative Conceptions. Research in Science Education, 40, 313-337.

[13] Kaltacki, D., Elyilmaz, A., \& McDermott, L. C. (2015). A Review and Comparison of Diagnostic Instrument to Identify Students' Misconceptions in Science. Eurasia Journal of Matheatics, Science, \& Technology Education, 11(5), 989-1008.

[14] Yana, A., Antasari, L., \& Kurniawan, B. (2019, Oktober 23). Analisis Pemahaman Konsep Gelombang Mekanik melalui Aplikasi Online Quizizz. Jurnal Pendidikan Sains Indonesia, 7(2), 143-152.

[15] Sutopo. (2016). Pemahaman Mahasiswa tentang Konsep-Konsep Dasar Gelombang Mekani. Jurnal Pendidikan Fisika Indonesia, 41-53. 